\title{
O lugar do feminino na construção do conceito de adolescência
}

\author{
The place of the feminine in the construction of the concept of adolescence
}

\begin{abstract}
Alberto Olavo Advincula Reis*, Fabiola Zioni**
REIS, A.O.A. \& ZIONI, F. O lugar do feminino na construção do conceito de adolescência. Rev. Saúde Pública, 27(6): 472-7, 1993. São discutidas as origens do conccito de adolescência procurando explicar aspectos críticos do conceito, como a presença hegemônica do pensamento bio-naturalista e a presença de um androcentrismo nocional na sua formulação. Destaca-se a pertinência dessa discussão no sentido de contribuir para uma assistência mais adequada aos adolescentes, além de colaborar para expansão do conceito de adolescência no campo da Saúde Pública.
\end{abstract}

Descritores: Adolescência. Antropologia cultural.

Nos mais diversos campos do conhecimento, a adolescência vem se constituindo $\mathrm{cm}$ objcto de interesse desde que as grandes transformações sociais, econômicas c culturais - que ocorreram, sobretudo, a partir da Segunda Guerra Mundial altcraram c redescnharam, de modo radical, o perfil cla moderna civilização ocidental. A área da saúde, mais especificamente, $\mathrm{tcm}$ cncampado, de mancira pioneira, diversos temas atinentes a cstc aspecto.

A pesar deste papel de vanguarda, a saúde tem, contudo, partillhado, com outras tantas árcas do conhecimento, do mesmo espírito de condescendência cpistemológica que implica considerar, de mancira imediatamente válida, a gencralidade do conccito de adolescência. Ora, um dos aspectos principais sobre o qual sc apóia tal gencralidade reside na extensão universal do conccito aos mundos feminino e masculino. Desta fcita, parece oportuno discutir o lugar $\mathrm{c}$ a cmergência do fcminino no conccito geral da adolescência, tal como cle ararece na produção tcórica da saúde.

O conccito de adolescência, amplamente accito nessa árca, foi definido na Rcunião da Organização Mundial da Saúde (OMS) sobre a gravidez c - aborto na adolcscência, realizada $\mathrm{cm} 1974$. Assim, de acordo com a OMS ${ }^{10}$, a adolcscência corresponde a um periodo $\mathrm{cm}$ que:

\footnotetext{
* Departamento de Saúde Matemo-Infantil da Faculdide de Saúde Pública da Univcrsidade de São Paulo - São Paulo, SP - Brasil

* Departamento de Prática cm Saúde Pública da Faculdade de Saúde Pública da USP - São Paulo, SP - Brasil
}

Scraratas/Reprints: A.O.A. Rcis. Av. Dr. Amaldo, 715 01246-904 - São Paulo, SP - Brasil

Edição subvencionada pela FAPESP. Processo Medicina 93/ 0208-5. a) o indivíduo passa do ponto do aparecimento inicial dos caractercs sexuais secundários para a maturidade scxual;

b) os processos psicológicos do indivíduo e as formas de identificação evolucm da fase infantil para a adulta;

c) a transição do cstado de đependênncia cconômica total passa a outro de relativa independência.

A OMS dî por entendido "que não se impõen limiles específicos à adolescência, c que cste termo corresponde a uma classificação social que varia tanto $\mathrm{cm}$ sua composição como $\mathrm{cm}$ suas implicaşõcs". No cntanto, considcra o pcríodo de adolescência como aquele comprecndido, aproximadamente entre os 10 e 20 anos (WIIO ${ }^{10}, 1975$ ).

Uma primeira leilura da definição $\mathrm{em}$ foco revela sua intenção essencial de contemplar as dimensões biofisiológica, psicológica c cconômica que levam o sujcito humano do estado infantil ao adulto. Entretanto, csta definição oferece algumas dificuldades. No plano fenomenológico, ć raro cncontrar pessoas, entre 10 c 20 anos, cujas transformações biopsicossociais ocorram de modo articulado c simultânco. Em termos da cxigência de homogencidade do objeto considerado, a definição de adolescência toma-sc confusa. Com cleito, querer articular o nívcl biológico, aos olhos do qual todo homem é como todos os outros homens, com o nível cconômico, onde todo o homem ć sob certos aspectos como alguns homens, c, finalmente, com o nível psicológico, onde nenhum ho$\mathrm{mem}$ é igual a outro hom $\mathrm{cm}$, conduz o problema a uma solıção que cstá longe de ser alcançada.

É provável que a dificuldade de se ter uma definição mais cocsa resida no fato de a saúde pública, que pode scr compreendida como campo de composição de várias práticas hetcrogêncas, não pos- 
suir nenhuma cspécic de teoria própria no interior da qual scus objelos possam ser devidamente conccituados. Em virtude disso, impöc-se a tarefa de proceder a um exame dos campos de conhecimento tangenciais ao da saúde que fornecem subsídios à formulação de sua idéia de adolescência.

A antropologia social vem, desde os anos 30 , ofcrecendo contribuiçõcs significativas à saúde ao centrar na socicdade o princípio de cxplicação do indivíduo. Em linhas gerais, ela afirma que, quando são poucas as divergências entre o conjunto de normas sociais impostas às crianças $c$ aos adultos, a passagem para a vida adulta ocorre scm atropelos. No caso de socicdades onde a cada grupo ctário correspondem papéis diferenciados, essa passagem será marcada por periodos de transição mais ou menos nílidos que podcrão implicar ritos de passagem, dramatização cpisódicas, conllitos intra $\mathrm{c}$ intcrindividuais*. Ao qucstionar a leitura "naturalizada" da ctapa conhecida como adolescência, a antropologia considera que cssa fase corresponderia mais a um fenômeno culturâl do que a uma incvitabilidade biológica. Em outras palavras, os comportamentos considerados como "naturais" na adolcscência cstariam mais ligados aos padrõcs culturais do que a determinadas condiçoces fisiológicas (Bencdict ${ }^{3}, 1952$ ).

A tcoria culturalista da antropologia, além de promover um enriquecimento conccitual pela adjunção do social à idéia de adolescência, criou, ainda, algumas condições intelectuais que permitiram uma depuração do referido conccito. Esta depuração se realizou atravćs da supcração dos aspectos bionaturalistas que intoxicavam a noção de adolescência. De fato, lais aspectos funcionavam como obstáculos, posto que consistiam $\mathrm{cm}$ produlos de uma subjetividade projetada no instrumento do pensamento objetivo que é o conccito. Em suma, para uma cultura $\mathrm{cm}$ que a paixão do visível constitui um dos traços essenciais de sua subjctividacle, o destronamento da dimensão biológica promovida pela corrente sociocultural da antropologia pode ser, genuinamente, considerado como um progresso da razão.

$\mathrm{Tcm}$-se, assim, que os fatos cvidentes agrupados sob as noções de pubcrdade c pubescência só adquirem valor e significado quando interpretados

A cultura ocidental moderna - muito cmbora registre, de mancira manifcsta, um padrão de graduação de idades - não forjou ritos c/ou procedimentos culturais explicitos e formais que marcassem as mudanças de "papel" e "status" sociais em função da idade. Provavelmente, nesse caso, tais ritos foram substituidos por dramatizaçôes psicológicas, vividas individualmente, capazes de levar o sujcito a um processo de redefinição pessoal cm função das exjgências sociais. socialmente. A adolescência pode ainda scr, em ccrtas sociedades, ignorada ou, ao contrário, $\mathrm{cm}$ outras, ser valorizada a ponto de mobilizar e catalisar em torno de si vastos setores dos comportamentos organizados do conjunto da socicdade. Decorre daí, ainda, que os cventos biopubertúrios, que marcam caractcristicamente tanto os meninos como as meninas, podem ser tratados, em nivel social, de mancira bastante diferenciada pelas ccrimônias ritualistas que celebram, em última instância, a adolcscência.

A despeito das conclusões desses estudos antropológicos apontarcm para a não naturalidade do fonômeno da adolescência como para a ausência de obrigatoricdade, de especularidade c contemporancidade entre a adolescência masculina e feminina, a cultura ocidental parece afirmar a existência de uma certa simetria na adolescência dos gêneros. Em oposição a csta noção de correspondência simétrica pode-se tambćm aventar a idćia de que somentc o atual cstígio de abstração do conccilo (associado à ênfasc dada à chamada "base fisiológica" da adolescência) ć que tcm permitido sua cxtensão universal ao gêncro. Em outros termos, haveria algo de inadequado no conccito de adolescência, quando aplicado indistintamente ao universo geral dos gêneros masculino c feminino.

Tal inadequação cstaria assentada no fato de a idéia de adolescência, no Ocidente, tor sido construída, essencialmente, a partir da consideraçĩo $\mathrm{c}$ da comprecnsão do conjunto histórico das expcriências masculinas. Desta forma, dado que cste androcentrismo nocional não cstá sendo aprecnsível nas formas atuais, abstratas $c$ depuradas do conccito, faz-sc necessária uma investigação de orientação genélica. Confirmando esta neccssidade, uma tendência crítica da antropologia atual aponta para o fato de que, apesar de importantes $c$ pionciras, as descobertas das tcorias culturalistas versaram, prioritariamente, sobre a visão c a experiência masculinas dessas culturas, "como sc tal experiência refletisse o todo cultural" (Mota ${ }^{8}$, 1980). Para discriminar cssa questão torna-sc fundamental entender - ainda que de mancira panorâmica - como criança c adolescentc se constitucm enquanto objeto de reflexão.

\section{Gênese da Infância e da Adolescência}

De acordo com os historiadorcs das mentalidades, até o Século XVIII a socicdade via mal a criança c, pior ainda, o adolescente (Arics², 1978). Para Aries, essa idćia confirmou-sc quando a pesquisa histórica se revelou capaz de demonstrar que - cmbora cm períodos anteriores à Idade Média tenha cxistido uma organização da comunidade 
por classes de idade - dessa época até o Século XVIII, a cultura ocidental abolira as distinções etárias. Na Idade Mćdia, a socialização, no interior das corporaç̃es, introduzia a criança no mundo adulto, dissolvendo paulatinamente as classes de idade. Assim, a própria noção de idade deixou de ser critério social significativo.

Com as drásticas mudanças socioeconômicas do Século XVIII, a escola substituiu a corporação em seu papel instrumentador e socializante. Através da escola a criança separou-se do adulto, o que permitiu que a noção de idade e de infância assumisse uma dimensão social mais significativa. Nesse período, o conceito de infância passou igualmente a se caracterizar pela sua longa duração. A extensão da infância implicou que, ao seu final, a criança entrasse diretamente no mundo adulto. Posteriormente, à sombra de duas instituições - a escola e o exćrcito - veio a germinar a noção de adolescência, criando uma forma de transição entre o "homem" c o "menino".

Alé o Século XVIII, a escola organizava-se de mancira bastante diferente da atual: significava mais abrigo de estudantes pobres do que instituições de ensino. Contudo, as exigências do Século XVIII inspiraram um movimento disciplinador, cuja extensão transformou a escola da época em um colégio encarregado do ensino, da vigilância e enquadramento da juventude. $O$ primeiro passo desse movimento foi separar as crianças menores das mais velhas, permitindo a identificação de uma fase cronologicamente postcrior à infância, de preparação à vida adulta: a adolescência.

Processo semclhante ao da escola ocorreu cntre os ofíciais no exćrcito do Sćculo XVIII. Para as hicrarquias inferiorcs, a situação somente scria revcrtida após a Primcira Gucra Mundial. Daí cm diante, a adolcscência se expandiria, cmpurrando a infância para trás e a maturidade para frente. Assim, a adolescência, figura do Sćculo XIX c do início do Século XX, teve na escola c no exército seus elementos concretos de formação. De mancira mais precisa, foi através da obscrvação das expcriências dessas duas instituições que a sociedade moderna pôde compor uma nova realidade psicológica, a adolescência.

Dessas instituições - do exército e da cscola - as mulheres estiveram, durante muito tempo, cxcluidas. $\mathrm{Na}$ atividade castrense, as mulheres somente se incorporaram, mutiladas, na imaginação ćpica dos homens, atravćs das fabulações amazônicas, ou, cntão, na realidade emblcmática de uma virgem salvadora, incapaz, contudo, de cscapar ao estigma fcminino da feiticeira: Joana D'Arc. Na gucrra e no exćrcito moderno, a elas foi permitido uma participação auxiliar nos corpos médicos. Florence Nightingale, no campo de Scu- tari, talvez tenha sido a primeira expressão desta modernidade. A participação feminina nas guerras contemporâneas veio, naturalmente, se dar fora do contexto da sociogênese da adolescência.

Não se discutem as razões nem as eventuais vantagens desta exclusão, mas tão somente as conseqüências referentes ao fato da exclusão feminina de instituições através das quais se operou uma nova repartição do ciclo de vida do homem ocidental. Excluídas do exército, as mulheres também o foram, por muito tempo, da escola. Quando tiveram acesso a essa instituição, foram mantidas, em sua maioria, fora de um verdadeiro processo de escolarização, constituindo um maciço bloco social que entrava diretamente para a vida adulta*.

\section{Infância e Adolescência no Brasil}

No Brasil, mais lento e ainda mais recente, o processo de constituição da adolescência esteve atrclado às características de sua formação social. As distinções cntre os tempos de vida, notadamente entre a infância e a idade adulta, dos escravos machos e fêmeas, dos homens e das mulheres brancas, ocorreram quase no beiral do Sćculo XX, numa outra cadência e seguindo detcrminações relativamente diferentes das da Europa, embora guardassem características globais análogas àquelas de lá.

Enquanto na Europa do Século XIX, o sentimento moderno de infância já havia há muito se instalado e se difundido e a adolescência começava a despontar diferenciando-se da criancice, vários viajantes, que naquela época estiveram no Brasil, destacavam o "ridículo da vida brasilcira", visto que "os meninos desde os nove anos trajavam-se como homens feitos $\mathrm{c}$ tinham como meta a de se sifilizarem o mais breve possivel" (Freyre? 1966)**. Mota $^{8}$ (1980) assinala que, para a criança escrava a idade de cinco anos marcava o término da infância.

Longe da disciplina da escola e da necessidade da força organizadora do exćrcito, o brasilciro tinha, ao contrário do europeu, nos ensaios do mando senhorial e na obediência do trabalho escravo a escanção dos tempos de vida. É assim que o filho

* Posteriormente, estabcleceu-se o costume de enviar as meninas às institujções religiosas com objetivo de inculcar-lhes, tão somente, instrução devota e "savoir faire" doméstico. A incultura constituiu um legado que a maioria das mulheres, deixada fora da escola, transmitia de geração em geração.

* Cerca de um sécule depois, meninos e meninas brasileiras asscmelham-se aos "adultos miniaturas" à época do "Ancien Regime". 
do Senhor de Engenho, chamado de menino diabo, até os 10 anos excrcitava-se, através de jogos brutais, nos exercícios do jugo, enquanto o filho do escravo ensaiava, nas cozinhas das casas grandes, o exercício da escravidão. A partir dos 10 e 12 anos entravam ambos, cada qual com sua sina, no mundo dos adultos.

Quanto às mulhcres, era comum casarem-se cedo. Se os 12 e 13 anos constituíam a norma, não cra raro que o aristocrata escravagista permitisse, infringindo suas próprias leis, que suas fillhas se casassem até com oito anos. Na educação, a clas dispensadas, obscrvava-se um atraso de um século ou mais sobre a norma curopćia. Das sinhas-moças, só sc espcrava o casamento. Deste modo, clas não só desconheciam a instituição escolar,como muitos pais, em casa, impediam-lhes o acesso às primciras Ietras. Criadas $\mathrm{cm}$ ambiente rigorosamente patriar$\mathrm{cal}$, clas viviam sob a mais dura tirania dos pais, depois substituída pela tirania dos maridos.

Segundo Freyre ${ }^{7}$ (1966), as belas meninas, cuja primeira comunhão marcava a entrada na vida adulta, tornavam-se, muito cedo, feias matronas de dezoito anos, carregadas de muito ouro, braceletes e pentes. Mrs. Grahan, na Bahia, nos anos de 1821 a 1823 , julgava-as "almost indecently slovenly after very carly youth" (Frcyre ${ }^{7} 1966$ ). De fato, o enveliccimento precoce das brasileiras devia-se, entre outras razõcs, à higiene escassa, à alimentação descquilibrada, à maternidade precoce e desassistida, à indolência e à mandriicc que o sistema social escravocrata impunha como norma ao corpo feminino.

Quanto à menina escrava, sua situação pode ser inferida da leitura de um manual de fazendciros do Sćculo XIX, segundo o qual a parte mais produtiva da propriedade escrava era o ventre gerador. Desta forma, o próprio interesse econômico favorccia uma vida sexual precoce e promíscua para as meninas negras, na medida em que suscitava, nos propriclários, imoderado desejo de possuir o maior númcro de crias (Freyre ${ }^{7} 1966$ ).

Escravas negras ou brancas livres, cm condições sociais distintas, entravam no universo do sexo $\mathrm{c}$ da reprodução biológica $\mathrm{cm}$ igual compasso $\mathrm{c}$ sob um registro onde primava a ausência de toda c qualquer valorização cspecial. Essa siluação de não reconhecimento se transformará, "a parlir do momento $\mathrm{cm}$ que a criança pequena $\mathrm{c}$ a mãe irão entrar na mira do movimento higienista" (Civilleti $\left.^{4}, 1991\right)$.

\section{A visibilidade da mulher e da criança e o movimento higienista}

Tanto no Brasil como na Europa, o conccito de adolescência pode ser entendido como "masculi- no" porque se constituiu a partir de experiências históricas concretas das quais as mulheres encontravam-se excluídas. No Brasil, a inclusão feminina no âmbito de experiências socialmente valorizadas e, conseqüentemente, dotadas de visibilidade, foi inaugurada pelo movimento higienista que criou condições - pelo menos parciais - para que, posteriormente, o conceito de adolescência fosse estendido ao mundo das mulheres. A contribuição dos higicnistas para essa extensão - que não significou desmasculinação do conceito - deve-se ao fato de que foram eles que tematizaram a situação social da mulher, ao se encarregarem de promover a transformação do modelo familiar brasileiro, principalmente em sua versão urbana.

No modelo familiar colonial urbano, a mulher da casa senhorial desempenhara um papel relativamente ambíguo dado que, apesar de analfabeta ou dc poucas letras, sem experiências fora do âmbito domćstico, a ela cabia o papel de administradora dessa "casa grande" "citadina", cuja função social extrapolava o simples abrigo familiar. Fechada dentro de casa, descuidada e não reconhecida pela sociedade, responsável por deveres muitas vezes supcriores às suas condiçð̃es etórias, contraditoriamente, a mulher representava uma peça chave na manutenção de uma determinada forma de vida social, papel esse mais complexo do que aquele que as relações sociais do tipo patriarcal fazcm supor à primeira vista. A sociedade urbana do Século XIX - alvo da atenção higienista - ainda se inspirava no padrão colonial caracterizado pela auto-suficiência da propriedade rural, que havia transposto para o meio urbano a casa senhorial e toda as relações sociais que se desenvolviam no scu interior. A casa brasileira, até meados do Século XIX, era um misto de unidade de produção e consumo. Boa parte dos víveres, utensílios domésticos e objetos pessoais necessários a uma famúlia eram fabricados na própria residência. A mulher gerenciava esta pequena empresa e se encarregava de suprir o escasso mercado de scrviços da cidade. A dona de casa cra enfermciro, médico, sacerdote e professor, representando, de certa maneira, a submissão da cidade à familia (Costa $\left.{ }^{5}, 1979\right)$.

Como decorrência deste fato, propiciava-se a perpetuação do modo de vida colonial que criava parentes no lugar de cidadãos. Essa siluação por sua vcz, não se apresentava como descjávcl para a conjuntura econômico-social dos meados do Século XIX. Em outras palavras, para transformar um agregado de propricdades rurais, regidas por interesses locais e voltadas exclusivamente para o comércio com a Metrópole, em um país dotado de um mínimo de integração, era necessário o desenvolvimento de um novo tipo de representação social sobre a maneira de se "viver a vida". Era ne- 
ccssário, cntre outras medidas, a criação de um outro padrão de relações familiares (Zioni Gomes c Adorno $\left.{ }^{11}, 1990\right)$.

A responsabilidade pela criação dessa nova familia coube à "Higienc, cntendida como parte da ciência mćdica que nos dá os preccitos $\mathrm{c}$ as regras nccessárias, tanto à aquisição como à conservação da saúde c se refercm a cxcrcícios, banhos, sonos, paixõcs [...], cnfim, cnsina a evitar coisas nocivas c a fazcr bom uso das coisas útcis" (Costa $\left.{ }^{5}, 1979\right)$. Para a normatização da vida cotidiana, a partir de condutas entendidas como naturais $\mathrm{c}$, portanto, descjávcis, o movimento higienista centrou sua atenção sobre a mulhcr.

A csposa que, no modelo familiar colonial, debruçava-se sobre a adminisuração da casa, descuidava-se da prole que ficava sob os cuidados dos escravos. Este lipo de relações familiares não parecia adequado à conjuntura político-cconômica de ruptura do pacto colonial. O Estado brasilciro - $\mathrm{em}$ vias de formação - buscava criar condiçőcs tanto para um projelo agroexportador $\mathrm{cm}$ moldes concorrenciais como para a formação de uma unidade nacional que substituísse a antiga relação proprictårio de tcrra/mctrópole. Para isso, scrvia-se do processo de higicnização scgundo o qual a cscrava jamais seria o ator adequado para descmpenhar o papel de disseminador de novos valores. Longe de ser vista como promotora de uma vida regrada e saudável, csla passou a scr cncarada como um dos antigos "maus hábitos" que devcriam ser eliminados das rcsidências. A casa higiênica foi um dos triunfos médicos na luta contra a família clássica, $\mathrm{cm}$ favor da mulher c das crianças" (Costa5, 1979).

Ao expulsar miasmas, insctos c cscravas de dentro da casa, a mulher - inspirada pela Higicne abandonou suas antigas funçőes produlivas internas $\mathrm{c}$ abraçou sua prolc, transformou-sc, assim, $\mathrm{cm}$ mãe "amantíssima" de filhos criados para uma vida mais pública, mais urbana $c$ menos domćstica. A higiene forneceu, portanto, modelo c argumento para que houvesse uma separação entre o domus c a polis, imprimindo a necessidade de construção de um clo de transição que ligasse a vida doméstica à vida pública, à vida cconômica $\mathrm{c}$ política. Esta passagem cra, necessariamente, um tempo de preparação, durante o qual a criança brasilcira se desprendia dos braços maternos antes de ingressar no mundo adulto.

$O$ processo de passagem, do qual cmerge a figura da adolescência, foi, presumivelmentc, aqui também, uma cxpcriência masculina. De fato, o mundo exlcmo à casa cra o da produção, do qual a mulher se retirara ao sc dirigir para uma casa vazia de cscravos c miasmas c repleta de filhos. Obscrva-se, pois, o processo contraditório que presidiu a cmergência da adolescência: $\mathrm{cm}$ primci- ro lugar foi o processo - de origem social - que permitiu que, $\mathrm{cm}$ nível do conhecimento, mulher e criança sc tornassem cntidades biológicas especílicas, passíveis de investigação e cuidados. Depois, o interesse pclo campo matcrno-infantil propiciou a cmergência da adolescência ao cindir a vida pública c a domćstica. Contudo, a separação, do intcrior da qual surge a adolescência, vcio tingi-la com as cores da masculinidade, uma $\mathrm{vez}$ que, tendo sido os homens os agentes destinados à produção, a eles foram alocados os rituais de passagem da domus para a polis.

\section{Considerações finais}

Ao se reconstruir as origens do conceito de adolescência verificou-se 0 peso do aspecto biológico/natural enquanto pode representar um obstáculo à necessária abstração conccitual. Um scgundo cmpecilho residiria no que, aqui, se denominou "androcentrismo nocional", ou scja, a consideração imediatamente válida do conccito de adolescência mesmo sendo este resultado da extensão universal das experiências limitadas ao gênero masculino. A dimensão feminina do conccito de adolescência perde-se ou se cnfraquece quando se cfetua uma extensão abusiva aos gêneros. A recuperação da dimensão do feminino, além de se colocar como desafio para aqueles que se preocupam com o conhecimento $\mathrm{e}$ as práticas desenvolvidas $\mathrm{cm}$ relação à adolescência, significa, provavclmente, um amplo remancjamento do próprio conccito cm questão.

Quando se $t \mathrm{~cm} \mathrm{~cm}$ perspectiva o quadro particular da produção tcórica brasilcira cabem algumas considerações adicionais acerca da discussão cnvolvendo o processo de reconstrução do conceito de adolescência. No Brasil, a comprecnsão dos temas de saúde pública sofreu um ccrto remancjamento, principalmente, a partir da década de 70 . Alé cntão, a primazia de uma mentalidade naturalista, transparecendo, por cxemplo, na ĉnfase biológica apenas o conccito de adolescência, cra inconteste (Rosen ${ }^{9}, 1958$ ). Tendências de transformação começaram a se manisfestar no scio deste pensamento tradicional (cujas origens remontam aos exilos advindos da aplicação no campo da saúde pública das grandes descobertas da cra bacteriológica) quando, a partir dos anos 70 , um clenco de questionamentos foram introduzidos neste campo de interscção disciplinar (Adorno ${ }^{1}, 1992$ ).

Dentre as mudanças opcradas no destronamento, relativo, da centralidade naturalista do pensamento sanitarista, destacam-sc a cmergência da discussão sociológica relativa aos detcrminantes do processo de saúde c doença $\mathrm{e}$ da análise das 
ciências políticas accrca das práticas de saúde pública, desvelando-as como forma de controle político-ideológico (Foucault ${ }^{6}, 1982$ ). Essas reflexōes foram, assim, descnvolvidas no contexto de transição das formas institucionais do Estado brasilciro $\mathrm{c}$ rcinvidicaçōcs de massa por mudanças sociais e pelo estabclecimento de dircitos plenos de cidadania.

Em tendo $\mathrm{cm}$ conta cste breve cenário, o prescnte artigo prcocupou-se $\mathrm{cm}$ adicionar um outro tipo de reflexão apto a introduzir uma nova modalidade de contribuição das ciências humanas para a discussão accrca da adolescência na medi$\mathrm{da} \mathrm{cm}$ que esta se define como objeto e campo do pensamento c práticas da saúde pública. São exemplos deste cuidado a contemporânea tematização do gênero e a rccuperação da tcoria culturalista atualizada pcla antropologia aliadas à incorporação da "história das mentalidades" na comprecnsão da adolescência enquanto fenômeno inscrito no campo da saúde pública. A investigação genćtica do conccito de adolescência constilui, assim, uma tentativa de procurar $\mathrm{cm}$ suas origens c vicissiludes a explicação para aspectos nodais da claboração tcórica que podem implicar limites ou problemas para a própria assistência sanitária ao adolescentc.

REIS, A.O.A. \& ZIONI, F. [The place of the feminine in the construction of the concept of adolescence]. Rev. Saúde Pública, 27(6): 472-7, 1993. The origins of the concept of adolescence are discussed with a view to explaning certain of its critical aspects such as the predominance of bio-naturist though and notional androcentrism in its development. The discussion of this theme seeks also to contribute to a more adequate assistance to adolescents as well as to on enlargement of the concept of adolescence as related to the field of Public Heallh.

Keywords: Adolescence. Anthropology cultural.

\section{Relerências Bibliográficas}

1. ADORNO, R.C.F. A trajetória do movimento e da participação: a conduta dos atores sociais em saúde. São Pau1o, 1992. [Tese de Doutorado - Faculdade de Saúde Pública da USP].

2. ARIES, P. Hisloria social da criança e da famllia. Rio de Janciro, Zahar, 1978.

3. BENEDICT, R. Palterns of culture. Boston, Sentry Edition. 1959.

4. CIVILETTI, M.C.P. Cuidados às crianças pequenas no Brasil escravista. Cad. Pesq., (76): 31-40, 1991.

5. COSTA, J.F. Ordem médica e norma familiar. Rio de Janciro, Graal, 1979.

6. FOUCAULT, M. Microfísica do poder. Rio de Janciro, Graal, 1982.

7. FREYRE, G. Casa grande e senzala: formação da familia brasileira sob o regime de economia patriarcal. 13. ed. Rio de Janeiro, Liv. José Olympio Ed., 1966.

8. MOTA, C.N. da. Por uma antropologia da mulher. Rev. Encontr. Civiliz. Bras., (26): 31-48, 1980.

9. ROSEN, G. A history of public heallh. New York, MD Publication, 1958.

10. WORLD HEALTII ORGANTZATION. MEETTNG ON PREGNANCY AND ABORTION IN ADOLES. CENCE. Geneva, 1974. Report. Geneva, 1975. (WIIO Techuical Report Scrics, 583).

11. ZIONI GOMES, F, \& ADORNO, R.C.F. Crescimento c descnvolvimento na prática dos serviços de saúde pública: revisão histórica dos conccitos de criança. Rev. Saúde Pública, 24: 204-11, 1990.

Recebido para publicação em 10.5.1993 Aprovado para publicação em 15.9.1993 